\title{
3 Past cover modulates the intense and spatially structured 4 natural regeneration of woody vegetation in a pastureland
}

\author{
5 Rafael da Silveira Bueno (1) - Daniel García - Mauro Galetti · Tommaso La Mantia
}

6 Received: 29 September 2019/ Accepted: 22 January 2020

7 (C) Springer Nature B.V. 2020

8 Abstract Vegetation natural regeneration after agri9 cultural abandonment is changing the landscape 10 patterns in many areas worldwide. However, the 11 expansion rate, spatio-temporal dynamics, and the role 12 of past vegetation cover in shaping such patterns are 13 still barely quantified in fine and meso scales. Here, we 14 aim to quantify the expansion rate and assess the 15 spatio-temporal patterns and the effects of past cover 16 on natural woody vegetation cover increase. We 17 sampled woodland and shrubland cover from 1992 18 to 2016 in 30 ha in a formerly managed pastureland in 19 Sicily, Italy. We combined field sampling, GIS tools, 20 and spatial analysis to assess the spatial structure

A1 Communicated by James D. A. Millington.

A2 Electronic supplementary material The online version of

A3 this article (https://doi.org/10.1007/s11258-020-01006-3) con-

A4 tains supplementary material, which is available to authorized users.

A5 R. da Silveira Bueno $(\bowtie) \cdot$ T. La Mantia

A6 Dipartimento di Scienze Agrarie, Alimentari e Forestali,

A7 Università degli Studi di Palermo (UNIPA), Palermo,

A8 Italy

A9 e-mail: rafael.dasilveirabueno@unipa.it

A10 R. da Silveira Bueno · M. Galetti

A11 Departamento de Ecologia, Universidade Estadual

A12 Paulista (UNESP), São Paulo, Brazil

A13 D. García

A14 Departamento de Biología de Organismos y Sistemas -

A15 UMIB, University of Oviedo, Oviedo, Spain dynamics and test the effects of past cover amount and type and distance from forest or nearest woody patch on the proportional expansion of natural regeneration. After 24 years, woody cover increased $68 \%$, despite the aggregated spatial structure in 1992 remaining almost unchanged in 2016. The past vegetation cover was the best predictor of woody vegetation expansion in two out of three plots. Distance to continuous forest and to the nearest woody patch, as well as cover type, was not relevant. Our study highlights the importance of fine- and meso-scale studies to reveal both the deterministic and stochastic facet of woody vegetation dynamics. Natural regeneration may strongly change landscape patterns even under constant herbivory pressure and long-term deforestation. The detection of cold and hotspots of regeneration provide an important prompt for the design of restoration programs and landscape management.

Keywords Landscape pattern - Natural regeneration $\cdot$ Scale $\cdot$ Spatial regression $\cdot$ Vegetation dynamics

\section{Introduction}

In the Mediterranean region, human land use has altered the cover, composition and spatial patterns of natural vegetation over millennia, in many cases

\begin{tabular}{|l|lll|}
\hline & Journal : Medium 11258 & Dispatch : 28-1-2020 & Pages : 14 \\
Article No. : 1006 & $\square$ LE & $\square$ TYPESET \\
MS Code : VEGE-D-19-00353R1 & $\checkmark_{\mathrm{CP}}$ & $\checkmark$ DISK \\
\hline
\end{tabular}


favoring annual and perennial herbaceous vegetation over woody vegetation (Pausas and Millán 2019; Plieninger et al. 2014). However, due to the current trend of land abandonment in rural areas, the natural recovery of woody vegetation on deforested land through secondary succession is highly expected, although frequently influenced by concomitant changes in major disturbance regimes, such as fire and herbivore pressure (Amici et al. 2013; Falcucci et al. 2007; Massa and La Mantia 2007). A process of succession such as this has long been described in floristic and phytosociological terms (e.g., Debussche et al. 1982; Ne'eman and Izhaki 1996), but the intrinsic spatial dynamics of woody vegetation over time and the mechanisms underpinning those dynamics are still poorly understood (Allen et al. 2016; Méndez et al. 2008; Quero et al. 2011). Even basic questions, such as how intense in magnitude and how fast woody vegetation recovery can be, still remain unsatisfactorily answered for mesic woodlands (but see Abadie et al. 2018; Álvarez-Martínez et al. 2014). Studies have focused mainly on analysis in extreme environments, such as semi-arid or mountain areas (Alodos et al. 2004; Bonet and Pausas 2004; MartínezDuro et al. 2010; Pueyo and Begueria 2007) or on herbaceous or shrub communities (Bashan and BarMassada 2017; Carmel and Kadmon 1999; La Mantia et al. 2008; Ne'eman and Izhaki 1996). Similarly, little attention has been devoted to the spatial structure acquired by woody vegetation during succession, whether aggregated or random (Carmel et al. 2001). This is a relevant gap in knowledge given that spatial patterns result from, and, therefore, may be informative of, cumulative ecological processes involving both responses to abiotic conditions and, especially, interspecific interactions (Carmel and Flather 2004; Garcia et al. 2011; Keitt 2003). This spatio-temporal pattern analysis has a number of applications in landscape management. For example, the identification of those areas with greater potential for passive restoration (i.e., vegetation expansion through natural regeneration) may optimize resource use for active restoration (e.g., seedling plantation), directing efforts towards areas with lower recovery potential or regeneration cold spots (Berdugo et al. 2017; Carmel et al. 2001; Holl et al. 2018).

Abiotic factors such as climate, topography and soil may influence vegetation expansion and induce nonrandom spatial structures even on a small scale
(Gallego Fernández et al. 2004; García et al. 2014; Pueyo and Begueria 2007), although abiotic influence on some tolerant species may be less significant (Bacaro et al. 2008; Getzin et al. 2008; Quero et al. 2011). In such cases, intensity and type of past land use, the amount and distribution of past vegetation cover, and biotic mechanisms become the main interrelated drivers of vegetation expansion, defining spatial resilience in a determined site (Allen et al. 2016; Carmel and Flather 2004; Holl et al. 2018). Vegetative growth (e.g., canopy expansion and clonal reproduction), and facilitation (e.g., when a small plant enables the recruitment of a larger one) are inherently dependent upon past cover (Bakker et al. 2004; Garcia and Obeso 2003). In turn, the process of seed dispersal in woody plants, which in many ecosystems such as tropical forests or in the Mediterranean is highly dependent upon animals (i.e., zoochory), may shape the spatial structure of woody recovery in different ways. On the one hand, most seeds are deposited at short distances from their source, thus, most recruitment and vegetation expansion is expected near source (González-Varo et al. 2017; Martínez and García 2015). On the other hand, depending on the degree of redundancy or complementarity of the dispersal vectors, dispersed seeds may eventually reach greater distances but might be conditioned by the existing woody cover in different levels (Bueno et al. 2013; Garcia et al. 2011; Jordano 2017). Notwithstanding the above, the spatial template generated by seed dispersal is often subject to subsequent modification by recruitment losses due to small-scale disturbances, such as seed predation and herbivory, or large-scale disturbances, such as fire (Baeza et al. 2007; Carmel and Kadmon 1999; Gómez-Aparicio 2008). Cover type (i.e., shrubland or woodland), therefore, may affect seed dispersal and recruitment. Shrubs may attract seed dispersers and seed predators, and may compete with or facilitate other plants differently than higher trees, the same being true for patches or isolated individuals (Andivia et al. 2017; Lasky and Keitt 2012; Olff et al. 1999). Consequently, studies that quantify expansion rates and spatial patterns of woody vegetation over time and relate them to pre-existing vegetation cover are necessary in order to reveal the footprints that the ecological processes driving secondary succession leave behind (Chuang et al. 2018; García et al. 2014; Holl et al. 2018). Furthermore, these studies may

\begin{tabular}{|l|lll|}
\hline & Journal : Medium 11258 & Dispatch : 28-1-2020 & Pages : $\mathbf{1 4}$ \\
Article No. : 1006 & $\square$ LE & $\square$ TYPESET \\
& MS Code : VEGE-D-19-00353R1 & $\checkmark \mathrm{CP}$ & $\checkmark$ DISK \\
\hline
\end{tabular}


contribute to disentangle the role of spatial effects (e.g., spatial autocorrelation and random dispersal) affecting vegetation expansion and dynamics, and can enhance the effectiveness of management plans of protected areas and the recovery of degraded sites ( $\mathrm{Hu}$ et al. 2012; Méndez et al. 2008; Quero et al. 2011).

Here we combined current field sampling, GISbased interpretation of sequential, high-resolution images (satellite and aerial photographs) and spatially explicit analysis to evaluate magnitude, spatial patterns and potential drivers of expansion (i.e., increase) relating to woody vegetation cover over 24 years in a Mediterranean woodland pasture. We sought to answer the following questions: How fast, in terms of the magnitude of expansion over time, does woody vegetation recover in pastureland? How dynamic is the spatial structure along such expansion? Are current cover and expansion spatially correlated with the amount of past woody vegetation cover? And to what extent might distance to the continuous forest and to the nearest woody patch affect cover expansion? Our study presents an appropriate system in order to seek answers to those questions as it combines relatively homogeneous abiotic conditions with an absence of fire, providing a clearer quantification of woody vegetation recovery potential and interpretation of vegetation dynamics due to major biotic processes, such as zoochory and herbivory.

\section{Methods}

Study site

The study was conducted at Alpe Cucco $\left(37^{\circ} 52^{\prime}\right.$ and $13^{\circ} 24^{\prime}$ ), a site located in the center of the "Bosco della Ficuzza, Rocca Busambra, Bosco del Cappelliere e Gorgo del Drago" nature reserve (hereafter FBCD), which is a 7397 ha protected area composing the last, large remnant of forest in western Sicily (Badalamenti et al. 2017; Gianguzzi and La Mantia 2004). The site is a 160 ha woodland pasture comprising seasonal pastures intermingled with woody vegetation, surrounded by forest patches (Fig. 1). The local climate is mesic Mediterranean, with an average rainfall of $850 \mathrm{~mm}$ concentrated mostly in autumn and winter, and mean annual temperatures of $14.3{ }^{\circ} \mathrm{C}$, with average temperatures of $9.4{ }^{\circ} \mathrm{C}$ in the coldest months
(January and February) increasing to an average of $23.5{ }^{\circ} \mathrm{C}$ in the hottest months (July and August).

Vegetation in Alpe Cucco corresponds to the MesoMediterranean type, based on a classification of altitudinal belts (Rivas-Martínez 2008). Surrounding forest patches are mostly composed of holm oak (Quercus ilex), downy oak (Quercus pubescens) and, to a lesser extent, maple (Acer campestre) and manna ash (Fraxinus ornus) (Badalamenti et al. 2017; Gianguzzi and La Mantia 2004). The woodland pasture is dominated by seasonal grasses and forbs (see Bianchetto et al. 2015 for a species list) with isolated shrubs and trees, and varied-sized patches of woody vegetation comprising mostly six fleshyfruited species (Pyrus amygdaliformis, Crataegus monogyna, Crataegus laciniata, Rubus ulmifolius, Rosa canina and Prunus spinosa) and, to a lesser degree, one dry-fruited shrub (Calicotome infesta), the two oaks and maple (Gianguzzi and La Mantia 2004). The site was subject to a reforestation program during the decade 1970-1980; individuals of Fraxinus angustifolia and Pinus halepensis, two species previously absent in the pasture, were planted in scattered patches and isolated individuals in a part of the Alpe Cucco area (Gianguzzi and La Mantia 2004). Extensive cattle (cow) raising has a long history in Alpe Cucco, and is still present nowadays, whereas an active pastureland management program including irrigation, plowing, and seeding was developed during the period 1960-1990. (A.S.F.D 1959; Bianchetto et al. 2015).

Sampling design

In September 2016, we established three $500 \times 200 \mathrm{~m}$ plots, each divided into 160 subplots of $25 \times 25 \mathrm{~m}$ (sampling unit) covering a gradient from continuous forest to woodland pasture (Fig. 1). The minimum and maximum distances between plot edges were $300 \mathrm{~m}$ and $510 \mathrm{~m}(700 \mathrm{~m}$ from the centroid). All plots extended over relatively homogeneous flat areas (average slope 15\%) with northern exposure. Plot 1 has an average altitude of $975 \mathrm{~m}$ ( \pm 17 SD), plot 2-1004 $\mathrm{m}( \pm 36)$ and plot 3$901 \mathrm{~m}( \pm 9)$, with maximum altitudinal difference between subplots of $190 \mathrm{~m}$ (880 to $1070 \mathrm{~m}$ a.s.l.) All plots are classified as having deep soils $(>100 \mathrm{~cm})$, sub-alkaline, clay-dominated vertic haploxeralfs (Raimondi 1983) and share mostly the same plant species.

\begin{tabular}{|l|lll|}
\hline & Journal : Medium 11258 & Dispatch : 28-1-2020 & Pages : 14 \\
Article No. : 1006 & $\square$ LE & $\square$ TYPESET \\
MS Code : VEGE-D-19-00353R1 & $\checkmark$ CP & $\checkmark$ DISK \\
\hline
\end{tabular}



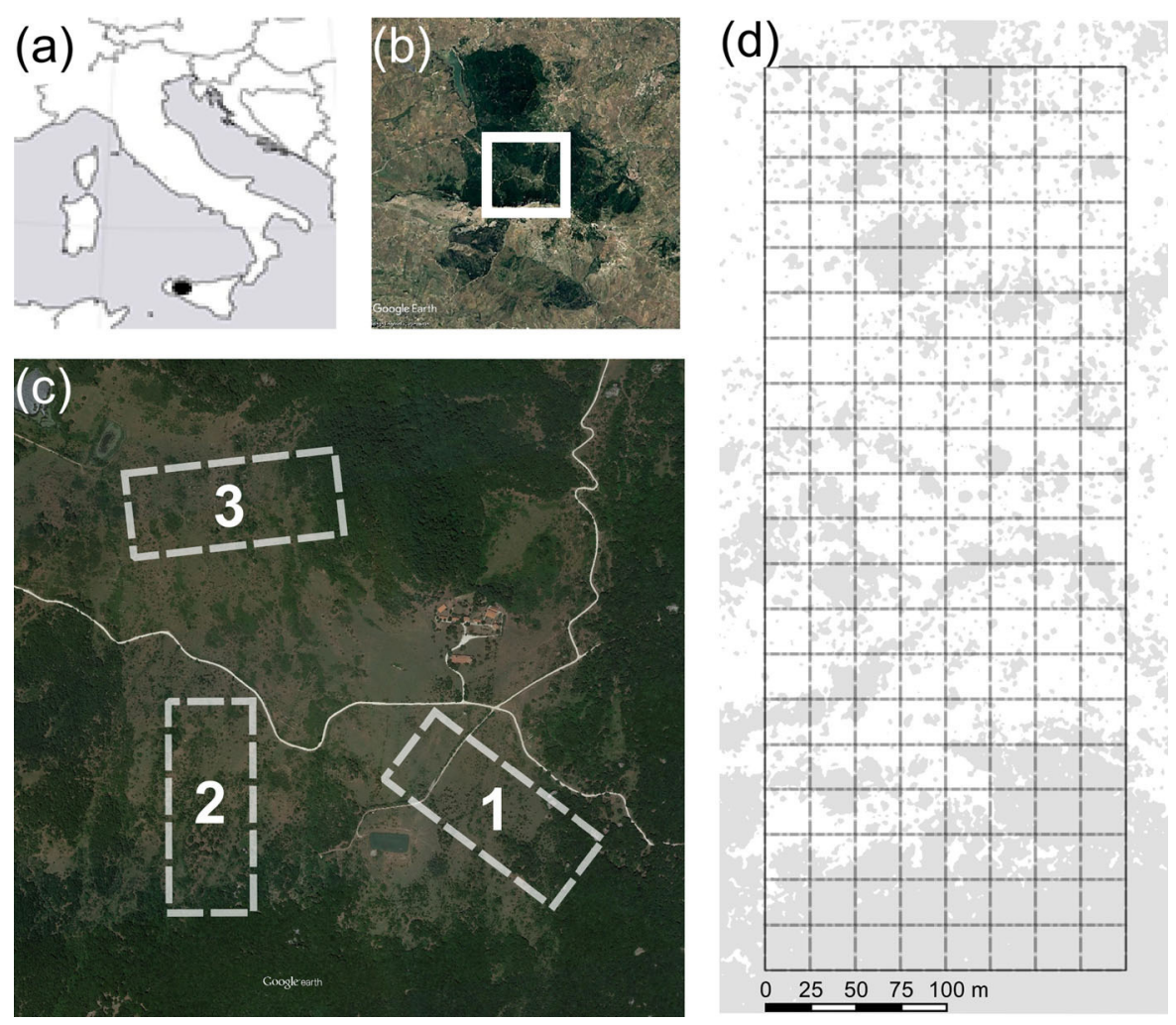

Fig. 1 a Location of the Ficuzza Reserve in Sicily (black spot). b Google Earth 2016 image showing the Ficuzza forest remnant and location of Alpe Cucco inside the reserve (white square). c Google Earth 2016 image with the three $500 \times 200$ m study

235 For example, the two most abundant tree species, $236 \quad$ P. amygdaliformis and C. monogyna have established 237 individuals scattered across $76 \%$ and $55 \%$ of the 238 subplots (Bianchetto et al. 2015; Bueno unpub. data). 239 Consequently, we assume that our plots are rather 240 uniform regarding key environmental features such as 241 precipitation, exposition, soil and temperature.

242 Vegetation mapping and classification

243 To measure the spatial pattern of woody vegetation 244 cover over the years, we contrasted aerial photogra245 phies from the year 1992 (scale 1:29,000, 1 pixel = $2461 \mathrm{~m}$ ) and satellite images from 2016 (Google Earth, 247 RGB bands, 1 pixel $=0.13 \mathrm{~m}$, rescaled to $1 \mathrm{~m}$ ), in a 248 time lapse of 24 years, incorporated into a Geograph249 ical Information System (GIS) platform belonging to 250 our study system (see Online Appendix S1 for details 251 of woody cover extraction procedure). Although older 252 images were available, the 1992 images were the plots established in the Alpe Cucco woodland pasture, covering the gradient from continuous forest to pastureland. $\mathbf{d}$ Example of the $160\left(625 \mathrm{~m}^{2}\right)$ subplot grids that was delimited inside each plot over the 2016 vegetation cover (light gray area)

oldest following cessation of pasture management, representing a conservative date to address vegetation recovery through secondary succession without further large-scale, human-provoked disturbance.

We sought to differentiate three types of woody cover in aerial views: woodland patches, shrubland patches, and isolated trees, shrubs and small nucleation patches of trees or shrubs (hereafter ITSN). In the 2016 extracted cover, woodland patches $\left(>50 \mathrm{~m}^{2}\right)$ were classified by contrasting with the original high-resolution image as well as by the heterogeneous dark gray texture which produced conspicuous black shadows (field checked as $>2 \mathrm{~m}$ in height) (see Online Appendix S1 and S2 for details). The species composing this vegetation type were Quercus pubescens, Quercus ilex, Acer campestris, Pyrus amygdaliformis, Crataegus monogyna, Crataegus laciniata, together with Fraxinus angustifolia and Pinus halepensis, two species naturally absent from the study area and that dominate the

\begin{tabular}{|l|lll|}
\hline & Journal : Medium 11258 & Dispatch : 28-1-2020 & Pages : 14 \\
Article No. : $\mathbf{1 0 0 6}$ & $\square$ LE & $\square$ TYPESET \\
& MS Code : VEGE-D-19-00353R1 & $\checkmark \mathrm{CP}$ & $\checkmark$ DISK \\
\hline
\end{tabular}


canopy cover wherever planted. Shrubland patches were defined as with an area of $>50 \mathrm{~m}^{2}$, homogeneous texture with a lighter-gray pattern compared to woodlands and which produced no conspicuous shadow $(<2 \mathrm{~m}$ tall), with or without trees. The species composing this cover type were Rubus ulmifolius, Prunus spinosa, Rosa canina and Calicotome infesta together with juveniles of P. amygdaliformis and $C$. monogyna. The remaining woody cover with a surface of $<50 \mathrm{~m}^{2}$ was classified as ITSN. All the woody vegetation cover extracted from the images was added as a new layer (polygons) to the GIS platform (Online Appendix S2). As the digital pixel value did not enable us to differentiate clearly between woodland and shrubland boundaries which occurred within the same polygon, we divided the 2016 and 1992 woody cover using photointerpretation, separating the different cover types into distinct polygons (Online Appendix S2). We had no reasons to correct the woody cover extraction output (i.e., no woody cover signed over the grassland or vice versa), but in order to validate cover-type classification and its boundaries, all polygons were numbered and checked in the field, where minor differences were corrected (accuracy $>98 \%)$; the subplot woody cover surface $\left(\mathrm{m}^{2}\right)$ of the different vegetation types was subsequently obtained (Online Appendix S2). Continuous forest, mainly comprising Quercus ilex and Quercus pubescens, was defined as a single woodland patch which contained the dense continuous woodland remnant surrounding Alpe Cucco. Distance predictors were calculated from the centroid of each subplot up to the nearest border of the continuous forest and to the nearest woodland patch (Online Appendix S2). According to the oldest aerial image available (1955), most plot surface was already deforested at that time (Online Appendix S3). As we were particularly interested in the expansion of woody cover due to natural regeneration, we differentiated the cover attributable to natural processes from that attributable to human-made plantation (see Pueyo and Begueria 2007 for a similar procedure; Appendix S2). Woody cover extraction, classification and figures were done using software QGIS (QGIS Development Team 2016).
Spatial structure of the woody vegetation cover over time

We were interested in characterize the degree of stability of the spatial structure of woody vegetation cover from 1992 to 2016. For this purpose we used the Spatial Analysis by Distance Index-SADIE (see Perry et al. 1999). SADIE uses a transportation algorithm to estimate the distance to regularity (D), that represents the minimum distances that the values of each spatially located variable (in our case woody cover in each subplot) need to move to reach a regular spatial distribution across all subplots, based on the concept of donors and receivers (Perry et al. 1999). The ratio between $\mathrm{D}$ and its average values, estimated through randomization, generate the global aggregation index (Ia) as well as its significance values at $95 \%$ confidence intervals $(p)$. An index around 1 indicate a randomly distributed woody cover, lower than 1 indicate regular distribution and higher than 1 represent an aggregated or patchy pattern. The $I a$ is composed by specific subplot clustering values (v), showing the magnitude of the contribution of each sampling unit to the overall cluster values and indicating if the cover value of a subplot is member of an above average patch ( $v i)$ or if a member of below average gap ( $v j$ ) (Perry and Dixon 2002; Perry et al. 1999). We calculated the SADIE aggregation indexes of the 1992 and 2016 woody vegetation cover separately (considering only the natural vegetation in 2016).

SADIE methodology also enabled us to quantify the spatial association index $(X p)$ of woody cover, derived from the mean values of 1992 and 2016 woody cover in the same subplot (i.e., correlation between the $v i$ and $v j$ indexes of both periods) (Perry and Dixon 2002). The index range from -1 to 1 and is significant if $p<0.05$, where a positive association means that the vegetation cover spatial distribution remained stable from 1992 to 2016 (both if a woody patch or a grassland gap), while a negative value means a mismatch of cover values along the 24 years (e.g., a grassland occupied by woody vegetation).

The next step was to exclude the planted cover to obtain values for proportional expansion of the natural regeneration cover from 1992 to 2016 (hereafter PE), calculated with the formula (2016 natural regeneration cover-1992 cover)/(625-1992 cover). We selected such relative variable instead of the amount

$\begin{array}{lll}\text { Journal : Medium 11258 } & \text { Dispatch : 28-1-2020 } & \text { Pages : } \mathbf{1 4} \\ \text { Article No. : } \mathbf{1 0 0 6} & \square \text { LE } & \square \text { TYPESET }\end{array}$


of increase to avoid the geometrical constriction of the quadratic relationship between available space and maximum cover increase. Thus, our PE represents the magnitude of cover expansion within each subplot in each $1 \mathrm{~m}^{2}$ unit, enabling the comparison of plots with different past covers independently from the absolute quantity of past cover within the subplot,. We then performed another SADIE analysis to obtain the spatial structure $(I a, v i$ and $v j)$ of PE. For this SADIE analysis, we excluded those subplots with full woody vegetation cover in 1992 and, consequently, zero expansion due to lack of space; there then remained 155 subplots in plot 1, 160 in plot 2, and 152 in plot 3. SADIE indexes are continuous variables (Perry and Dixon 2002), thus we incorporated the $v i$ and $v j$ indexes of 1992 and 2016 cover, and those of PE into bi-dimensional contour maps to obtain a more comprehensive view of the spatial pattern structure and to visualize coldspots (i.e., areas with zero or low cover increase) and hotspots (i.e., areas with high cover increase). Sadie aggregation indexes were obtained with SadieShell 2.0 and the spatial association was calculated with N_AShell 1.0 (Perry et al. 1999). Contour maps were prepared using the plugin contour of the software QGIS (QGIS Development Team 2016).

Factors affecting the expansion of woody vegetation cover

We sought to assess whether the quantity, identity and spatial configuration of past woody vegetation cover affected its further expansion over the 24 years period of study. Thus, we used multiple regression models, including the values of PE at the subplot level as a response variable and the amount of woody vegetation cover, distance to the continuous forest and distance to the nearest woodland in 1992 as continuous predictor variables. We also incorporated, as a qualitative predictor, the cover type in the 1992 subplot, classified as 0 if there was no cover, 1 for ITSN, 2 for shrubland, 3 for mixed cover (2 or more types) and 4 for woodlands). Cover type 1, 2 and 4 were defined if reaching $>70 \%$, otherwise was mixed. We excluded the subplots with full cover in 1992 and those with negative PE values (i.e. ,entreatment of woody vegetation cover) from the analysis, resulting in 145 subplots in plot 1,152 in plot 2 and 152 in plot 3 . PE was square-root transformed to achieve normality and reduce heteroscedasticity. Before running regressions we tested for multicollinearity among predictors using the variance inflation factor (mean $=2.73$, highest $=4.11$ ) and the three continuous predictors (amount of woody vegetation cover, distance to the continuous forest and distance to the nearest woodland in 1992) were standardized prior to the analysis. The model was calibrated and validated by correlating the measured and predicted PE values across all plots, with $p<0.001$ in all cases (Online Appendix S5).

As sampling included the use of spatially contiguous subplots, and vegetation expansion may present a contagious pattern (e.g., Bakker et al. 2004), we tested for the presence of spatial autocorrelation (Dormann et al. 2007; Keitt et al. 2002). Initially, we performed a global (all plots) and independent (each plot) nonspatial ordinary least squares (OLS) multiple regressions. Once all OLS models presented strong spatial autocorrelation (Moran's I $p<0.001$; Online aApendix S5), and this issue can cause strong bias in the results (Dormann et al. 2007; Kissling and Carl 2008) we discarded OLS results and tested both Spatial AutoRegressive Lag and Error Models (SARlag or SARerror). These regression analysis takes into account spatial autocorrelation in data through a weight matrix that incorporates the neighborhood values of that location (SARlag) or of the errors (SARerr) (Kissling and Carl 2008; Ver Hoef et al. 2018). In our case, the weight matrix was row standardized and based on different distance classes of neighbor points (subplot centroids), starting at $36 \mathrm{~m}$, which included all the immediate surrounding neighbors (borders and vertex first order) and the consequent orders of neighbors at each $36 \mathrm{~m}$ distance class. Due to our sampling design (spatially discontinuous sets of equally spaced grids), the differences in the weight matrix among plots (Online Appendix S5) and the objective to test for meso-scale differences in vegetation expansion, we ran independent SAR models for the different plots. The best model from SARlag and SARerr was selected based on lowest AICc, highest log-likelihood values, minimum residual spatial autocorrelation and model fit (pseudo- $R^{2}$ ). All the spatial tests and regressions were performed with GEODA 1.8 (Anselin et al. 2006).

\begin{tabular}{|l|lll|}
\hline & Journal : Medium 11258 & Dispatch : 28-1-2020 & Pages : $\mathbf{1 4}$ \\
Article No. : 1006 & $\square$ LE & $\square$ TYPESET \\
& MS Code : VEGE-D-19-00353R1 & $\checkmark \mathrm{CP}$ & $\checkmark$ DISK \\
\hline
\end{tabular}




\section{Results}

460

461

462

463

464

465

466

467

468

469

470

471

472

473

474

475

476

477

478

479

480

481

482

483

484

485

486

487

488
From 1992 to 2016, the overall woody vegetation cover in the three plots increased by 6822 ha $(90.1 \%)$, rising from 7568 to 14,390 ha. Most of the increase was due to natural regeneration (5159 ha), including 2849 ha of woodland, 2164 ha of shrubland and 0146 ha of ITSN (Fig. 2, Online Appendix S4). However, proportionally (i.e., increase relative to initial cover), shrubland almost doubled in surface $(94.9 \%)$, followed by woodland $(67.1 \%)$ and ITSN (14.1\%). Planted cover accounted for the remaining $24.4 \%$ (1663 ha). We found no correlation between 2016 planted cover and woody vegetation cover in 1992 (Pearson $r=-0.01, p=0.69$ ), suggesting that the development of planted cover occurred almost exclusively throughout the 24 -year period. The three plots differed in the average proportional expansion of natural regeneration woody cover (ANOVA $F=45.94, p<0.001$ ) with contrasting variations in each cover-type contribution to expansion (Fig. 2).

Spatial structure of the woody vegetation cover over years

The SADIE $I a$ index indicated that global spatial structure of woody vegetation cover was significantly aggregated and remained stable over time (from 1992 to 2016) (Table 1). Furthermore, the significant $X p$ index indicated a strong spatial correlation between $v i$ and $v j$ values in the same subplot over time, denoting a conservative, small-scale spatial trend in vegetation dynamics (i.e., few subplots members of a gap became

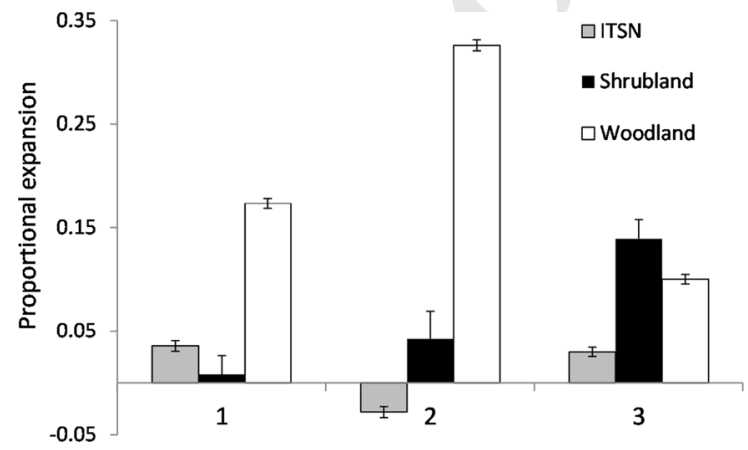

Fig. 2 Average ( \pm SE) subplot values of proportional expansion (PE) of isolated trees, shrubs, and small nucleation (ITSN), shrubland, and woodland patches in plots 1, 2 and 3 from 1992 to 2016
Table 1 Summary of SADIE analysis

\begin{tabular}{|c|c|c|c|c|}
\hline \multirow[t]{2}{*}{ Plot } & \multicolumn{2}{|l|}{$I a$} & \multirow{2}{*}{$\begin{array}{l}X p \\
1992 \times 2016\end{array}$} & \multirow{2}{*}{$\begin{array}{l}I a \\
\mathrm{PE}\end{array}$} \\
\hline & 1992 & 2016 & & \\
\hline 1 & $5.69 * * *$ & $5.89 * * *$ & $0.89 * * *$ & $4.25 * * *$ \\
\hline 2 & $4.42 * * *$ & $4.38 * * *$ & $0.65 * * *$ & $3.91 * * *$ \\
\hline 3 & $5.72 * * *$ & $5.19 * * *$ & $0.79 * * *$ & $2.76^{* *}$ \\
\hline
\end{tabular}

Index of aggregation $(I a)$ and spatial association index $(X p)$ of the 1992 woody cover and 2016 natural regeneration woody cover, and the index of aggregation of the proportional expansion (PE) of natural regeneration woody cover in the three study plots $(* * * p<0.001, * * p=0.003)$

members of a patch or vice versa) (Table 1). The PE aggregation index also showed positive and significant values across plots, suggesting marked patchiness in the distribution of woody vegetation cover expansion within each plot, with no clear sign of broad, gradientlike spatial structure from the continuous forest towards open areas (Table 1; Fig. 3).

Factors affecting the expansion of woody vegetation cover

The SARerr model showed the best fit in comparison with SARlag models in all plots when assessing the effects of past cover, distance to continuous forest, distance to nearest woody patch and cover type on the proportional expansion of the natural regeneration of woody vegetation (Online Appendix S5) and subsequent results refers to this model. Woody cover in 1992 was the strongest predictor of proportional expansion (PE) across all plots, with a positive and significant effect in plots 1 and 2 (Table 2; Fig. 4). Distance to the continuous forest showed no significant effect on PE in any plot (Table 2). However, PE tended to increase at shorter distances from the nearest woody patch, as illustrated by the negative coefficient values of this predictor across plots $(p=0.07$ in plot 1 ; $p<0.001$ in plot 2). PE was also independent of the type of woody vegetation cover in all plots (Table 2).

\section{Discussion}

In our study, we quantified the intensity of woody cover expansion and revealed, on the one hand, overall maintenance of the aggregated spatial pattern of

\begin{tabular}{|l|lll|}
\hline & Journal : Medium 11258 & Dispatch : 28-1-2020 & Pages : 14 \\
Article No. : $\mathbf{1 0 0 6}$ & $\square$ LE & $\square$ TYPESET \\
& MS Code : VEGE-D-19-00353R1 & $\checkmark \mathrm{CP}$ & $\searrow$ DISK \\
\hline
\end{tabular}


Fig. 3 Contour maps showing the SADIE aggregation indexes of the 1992 woody cover, 2016 natural regeneration woody cover, and the natural regeneration proportional expansion (PE) for the three study plots. The legend shows the specific subplot aggregation index $v i$ and $v j$ value ranges
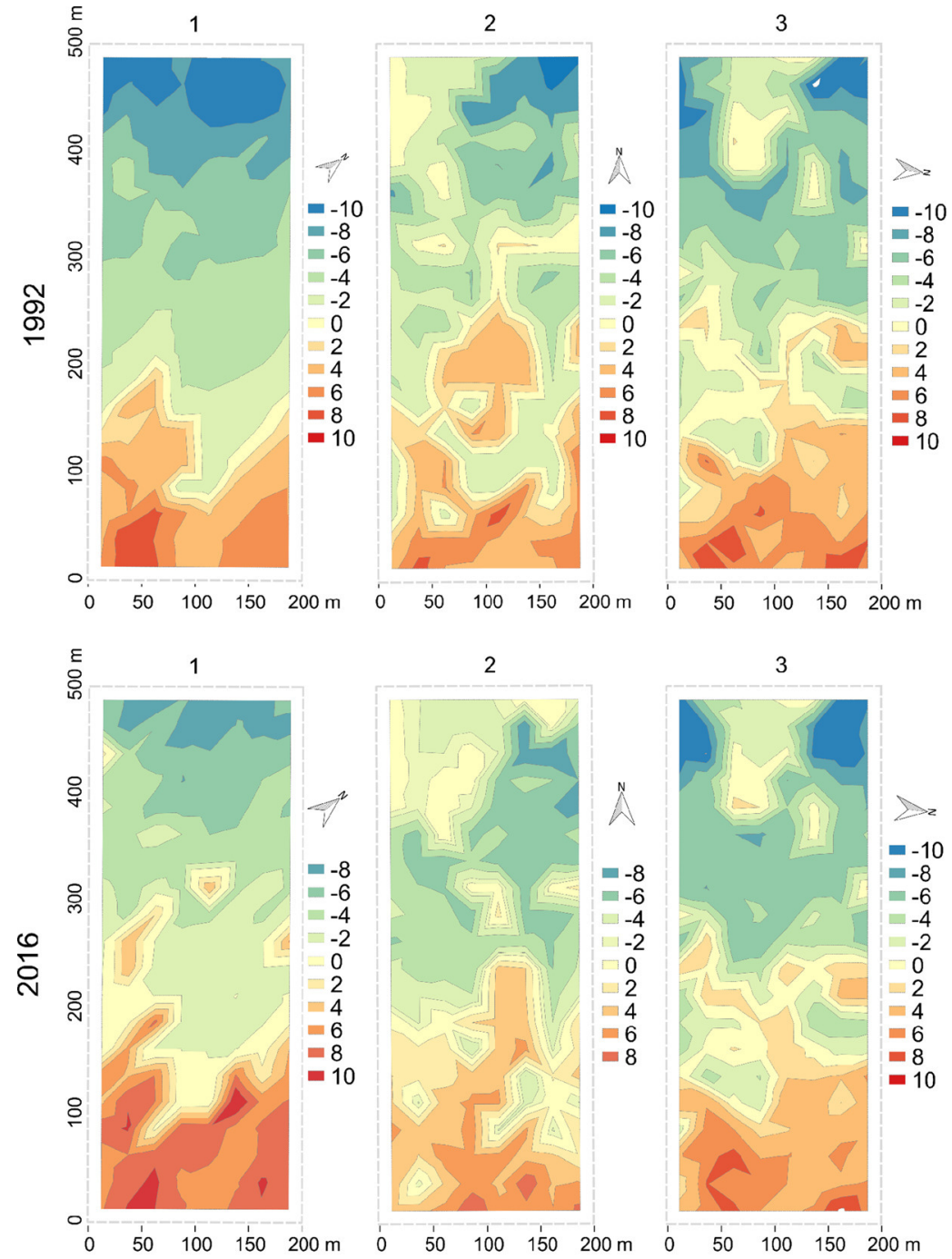

2

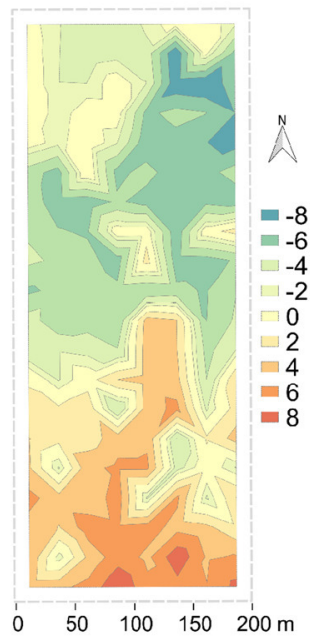

3

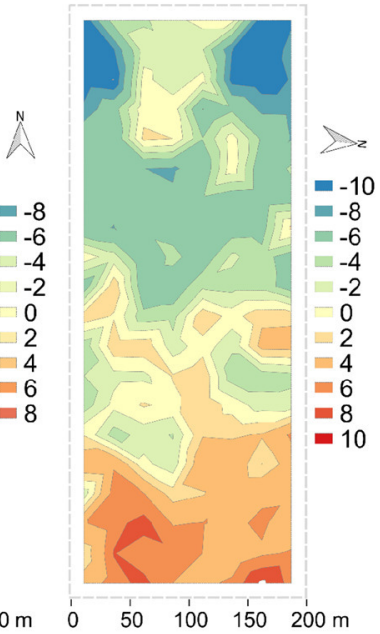

2
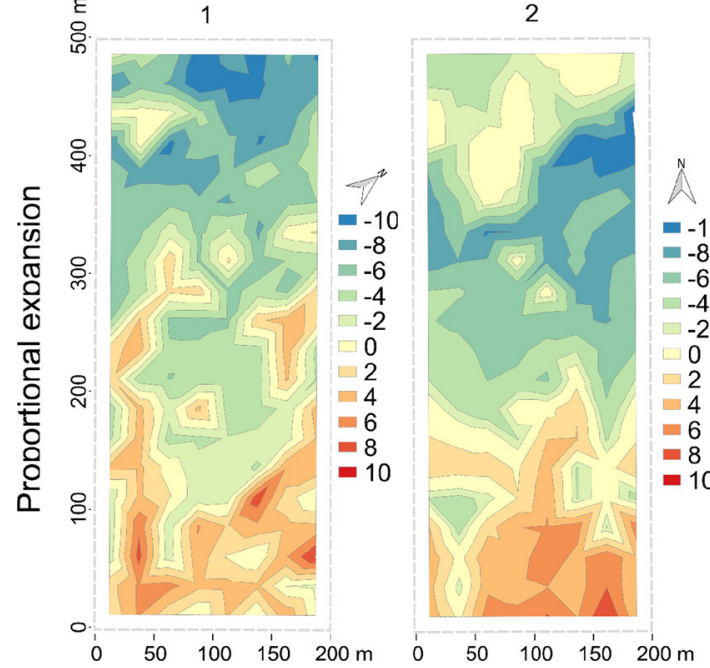

3

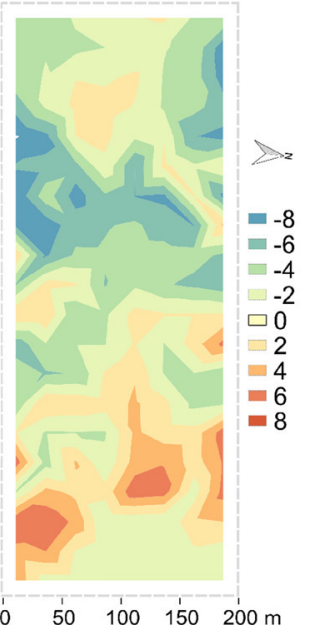

\begin{tabular}{|l|lll|}
\hline & Journal : Medium 11258 & Dispatch : 28-1-2020 & Pages : 14 \\
Article No. : 1006 & $\square$ LE & $\square$ TYPESET \\
MS Code : VEGE-D-19-00353R1 & $V_{\mathrm{CP}}$ & $\checkmark$ DISK \\
\hline
\end{tabular}


Table 2 Summary of the results of the SARerr model in the three study plots with the pseudo- $R^{2}$ showing model variance explanation of the proportional expansion of natural regeneration woody cover

\begin{tabular}{|c|c|c|c|c|c|}
\hline & Predictor & Coefficient & Standard error & $z$ & $p$ \\
\hline Plot 1 & Constant & 0.337 & 0.031 & 10.898 & $<0.001$ \\
\hline \multirow[t]{5}{*}{$R^{2}=0.61$} & Past woody cover & 0.124 & 0.028 & 4.479 & $<0.001$ \\
\hline & Distance continuous & -0.004 & 0.030 & -0.139 & 0.889 \\
\hline & Distance woody patch & -0.051 & 0.028 & -1.825 & 0.068 \\
\hline & Cover type & 0.019 & 0.016 & 1.142 & 0.254 \\
\hline & Lambda & 0.345 & 0.117 & 2.947 & 0.003 \\
\hline Plot 2 & Constant & 0.612 & 0.067 & 9.132 & $<0.001$ \\
\hline \multirow[t]{5}{*}{$R^{2}=0.63$} & Past woody cover & 0.077 & 0.019 & 4.138 & $<0.001$ \\
\hline & Distance continuous & -0.037 & 0.048 & -0.780 & 0.436 \\
\hline & Distance woody patch & -0.068 & 0.020 & -3.376 & 0.001 \\
\hline & Cover type & -0.008 & 0.016 & -0.516 & 0.606 \\
\hline & Lambda & 0.800 & 0.082 & 9.708 & $<0.001$ \\
\hline Plot 3 & Constant & 0.485 & 0.053 & 9.080 & $<0.001$ \\
\hline \multirow[t]{5}{*}{$R^{2}=0.24$} & Past woody cover & 0.054 & 0.039 & 1.376 & 0.169 \\
\hline & Distance continuous & -0.008 & 0.037 & -0.209 & 0.835 \\
\hline & Distance woody patch & -0.010 & 0.032 & -0.314 & 0.753 \\
\hline & Cover type & 0.018 & 0.023 & 0.761 & 0.447 \\
\hline & Lambda & 0.445 & 0.109 & 4.101 & $<0.001$ \\
\hline
\end{tabular}

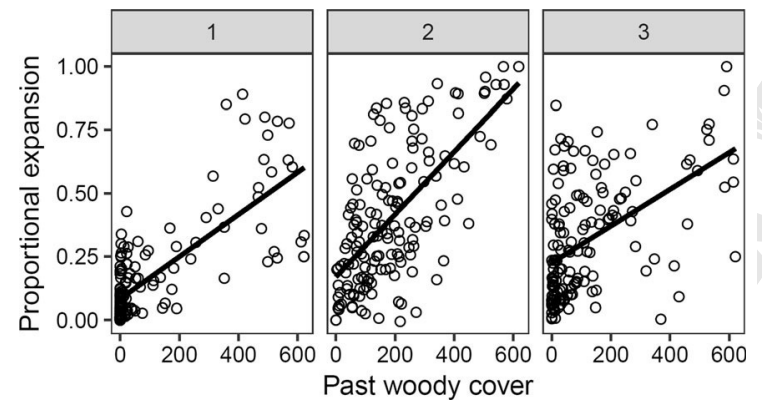

Fig. 4 The relationship between 1992 past woody cover $\left(\mathrm{m}^{2}\right)$ and proportional expansion of natural regeneration woody cover in plots 1, 2, and 3 expressed in a simple linear regression. Each dot represents a different subplot within the plot woody vegetation cover over 24 years, even under strong expansion. On the other hand, we detected quantitative (i.e., cover expansion) and qualitative (i.e., cover type composing the expansion) differences even in closely located plots. The increase in natural woody vegetation found in our study would seem to be relatively high, considering the current structural complexity of varied-size woodland and shrubland patches, and the deforestation, anthropic use and herbivory pressure, at least over the last 80 years inside the plots (Bianchetto et al. 2015).
Woody vegetation natural regeneration

It has been demonstrated that livestock herbivory can slow down or even hamper woody vegetation recovery (Carmel and Kadmon 1999; La Mantia et al. 2013; Laskurain et al. 2013). No precise information on cattle density was available for our site, nor regarding the increasing population of fallow deer (Dama dama) (Bianchetto et al. 2015), thus limiting our interpretations. However, judging by the observed recovery rate, no significant negative influence of herbivory in cover expansion seems to be occurring, at least over the past 24 years. A similar outcome was also observed in other Mediterranean areas (e.g., Bashan and BarMassada 2017). Besides the magnitude of expansion, the quality of vegetation recovery in our study system also differed from other studies in the Mediterranean region. Bonet and Pausas (2004), for example, found an average woody vegetation cover increase of $26 \%$ after 60 years; however, less than $20 \%$ of that cover was composed of endozoochoric species, while La Mantia et al. (2008) found an increase of $57 \%$, comprising mostly one dry-fruited species. On our site, the $68 \%$ natural regeneration woody cover increase was composed mainly of a mix of six zoochoric species (Pyrus amygdaliformis, Crataegus laciniata Crataegus monogyna, Rubus ulmifolius,

\begin{tabular}{|l|lll|}
\hline & Journal : Medium 11258 & Dispatch : 28-1-2020 & Pages : $\mathbf{1 4}$ \\
Article No. : $\mathbf{1 0 0 6}$ & $\square$ LE & $\square$ TYPESET \\
& MS Code : VEGE-D-19-00353R1 & $\square_{\mathrm{CP}}$ & $\checkmark$ DISK \\
\hline
\end{tabular}


Prunus spinosa, Rosa canina) (R.S.Bueno unpub. data).

558 Spatial structure of the woody vegetation cover

559 over years

560 Our SADIE analysis demonstrated that the woody 561 vegetation cover kept its highly spatially aggregated 562 pattern on both a landscape (plot) and a local (subplot) 563 scale throughout the 24 years, even when faced with 564 considerable expansion (Table 1). The maintenance of 565 aggregated patterns is the expected result of expansion 566 from previous cover (Bakker et al. 2004). In fact, past 567 woody cover positively influenced vegetation expan568 sion in plot 1 and 2 (Table 2; Fig. 4). In addition to the 569 effects of past cover, herbivory intensity may be one of 570 the factors not measured here that can influence 571 vegetation spatial configuration, although a range of 572 responses has been found so far (Adler et al. 2001; 573 Bashan and Bar-Massada 2017). Seifan and Kadmon 574 AQ2 (2006), for example, found that cattle herbivory 575 changed the spatial pattern of a scrub community by 576 reducing the aggregation level (clumpiness), although 577 the cover increase was not affected by different levels 578 of herbivory intensity. In our study, we found that the 579 aggregated pattern remained unchanged, while cover 580 expansion varied among plots sharing the same 581 herbivory pressure (Fig. 2).

582 Influence of past cover, cover type and distance 583 to remnant vegetation
Grass cover and canopy closure (i.e., a proxy of woody cover) were deemed to be the most relevant predictors in tropical forest recovery (Holl et al. 2018), although differential influences of past cover have been found across Mediterranean-type ecosystems (Carmel and Flather 2004). On our site, we found a differential contribution of past cover at plot scale, once this predictor was found to be non-significant in explaining expansion in plot 3 (Table 2). This plot showed some large patches resulting from the direct colonization of open ground, far from any previous woody vegetation cover, and this would explain the lack of effect of past cover in the regression model, as well as the lowest SADIE aggregation index. Another fact potentially affecting the lack of effect of past cover on expansion is that some types of early woody cover can themselves impede further development of ecological succession (i.e., arrested succession) (Acácio et al. 2007). On our site, for example, a number of $R$. ulmifolius patches remained almost unchanged over the 24 years, and a few large, old trees had virtually no vegetation increase in their surroundings. In the first case, the absence of cover increase in bramble patches may derive from a strong competitive effect (Fotelli et al. 2001). In the case of isolated large trees, the lack of structure for facilitating protection against herbivory, such as basal branching and protective spiny leaves at the ground level (Garcia and Obeso 2003) could explain the above pattern.

Contrary to our expectations, distance from the continuous forest proved non-significant in predicting vegetation expansion. Remnant forests usually act as a source of propagules for the colonization of open areas. Therefore, given the overall distance constraints of seed dispersal, a decreasing rate of vegetation expansion when moving away from the forest is expected (García et al. 2014). Our sampling design, with plots sharing similar configuration of continuous forest (one side forest), should be effective to check for distance effects by forcing a very large distance gradient in sampling points without lateral influence. However, on our study site, the continuous forest comprised mostly oaks ( $Q$. pubescens and $Q$. ilex), while the majority of the mid-successional woody plants species composing the bulk of cover increase were located mostly in pastureland. For example, one of the most important species in terms of cover expansion ( $P$. amygdaliformis) occurs at very low density inside the forest and is dispersed almost exclusively by mammals (Fedriani et al. 2010); therefore, even the longest distances within plots (ca. $1400 \mathrm{~m}$ ) can fall within the mammals seed dispersal potential (González-Varo et al. 2017). Complementarily, a recent study in Mediterranean has verified no differences in seed arrival in old fields of species dispersed by both birds and mammals up to $90 \mathrm{~m}$ from the seed source (La Mantia et al. 2019). In addition, higher fruit availability in woodland pasture compared to continuous forest coupled with vegetation structural complexity (i.e., presence of different perches and woody patches) may influence the behavior of those birds acting as seed dispersers, fostering movement away from the forest and towards fruit-rich environments (La Mantia and Bueno 2016; Lasky and Keitt 2012). However, later in the process of secondary succession, an increase in the influence of distance to

\begin{tabular}{|l|lll|}
\hline & Journal : Medium 11258 & Dispatch : 28-1-2020 & Pages : 14 \\
Article No. : 1006 & $\square$ LE & $\square$ TYPESET \\
MS Code : VEGE-D-19-00353R1 & $\checkmark$ CP & $\checkmark$ DISK \\
\hline
\end{tabular}


continuous forest in cover species composition is expected, when the mid-successional species composing current expansion facilitate oak establishment in woodland pasture (Alias et al. 2010; Amici et al. 2013).

Distance to woody patch, in turn, was found to negatively affect the expansion of woody vegetation; however, this pattern was only significant in plot 2. A negative influence was expected established that proximity to even small patches of woody vegetation is a proxy for higher seed rain and consequent recruitment (Martínez and García 2015; NavarroGonzález et al. 2013). The initial configuration of woody vegetation in plot 2 , with many scattered, small patches, would have strengthened this negative relationship. The lack of relationship in the other two plots may derive, firstly, from a random distribution of mammal dispersed species (e.g., P. amygdaliformis) at this spatial scale. Secondly, the average distance range between patches may be easily covered by birds, resulting in a cover-cover directed seed dispersal (i.e., from a perch to another perch), with a consequent gap in recruitment between close patches (Garcia et al. 2011; Pausas et al. 2006). Refining the scale of the study using smaller subplots should provide additional information, although a species-specific differential response of each plant is also expected.

Woody cover expansion was independent of the type of patch composing the past cover, suggesting that, in our system, small patches of isolated trees and shrubs have the same potential to promote or prevent expansion as larger patches of shrubland and woodland. Moreover, we also observed subplots free of woody vegetation in 1992 occupied by woodland patches in 2016. For example, most oak-dominated woodland patches showed smaller expansion than mixed shrubland patches, probably an outcome of selective grazing and browsing (Carmel and Kadmon 1999; Garcia and Obeso 2003). On our site, palatable, late successional species (e.g., Quercus sp.) were almost absent from the woody cover under expansion, and mid-successional and herbivore-defended species are actually those developing woodland. Autoregressive parameters (lambda) obtained in our models, however, indicate that other factors not measured in our analysis are influencing cover expansion, a similar outcome was found also for species distribution $(\mathrm{Hu}$ et al. 2012). This strong neutral effect corroborates the importance of taking autocorrelation into consideration in spatial analysis (Ver Hoef et al. 2018).

Large-scale approaches are necessary in order to detect landscape and global patterns (Sluiter and de Jong 2007). However, considering the similarities (e.g., the aggregated spatial structure) and the differences (e.g., variation in the dominant cover type composing expansion) in closely located plots which share the same historical contingency, pool of species, grazing pressure and environmental conditions, the patterns found in our study highlight the complementarity of smaller scale investigations when interpreting vegetation dynamics and recovery ( $\mathrm{Hu}$ et al. 2012; Quero et al. 2011). As an example, in an applied perspective, this complementarity may refine the calculation of ecosystem services, such as carbon stock, it may improve the evaluation of scale-dependent species richness patterns and, consequently, help design more effective restoration programs (Chuang et al. 2018; Méndez et al. 2008; Novara et al. 2017). Finally, we demonstrate that in favorable conditions, especially in the presence of remnant woody cover and in the absence of fire, even a long history of deforestation, land use and the presence of livestock do not crush the potential for intense woody vegetation expansion, even though previous cover tends to "sequester" this potential for recovery.

Acknowledgements We thanks Giovanni Giardina for sharing helpful information regarding the history of Ficuzza and the Sicilian Dipartimento Regionale dello Sviluppo Rurale e Territoriale for the logistical support. Funding: RSB received a Ph.D. fellowship from the University of Palermo. Fieldwork and TL were funded by Italian "Ministero dell'Istruzione dell'Università e della Ricerca" (CARBOTREES201049EXTW). DG was supported by Spanish "Ministerio de Economía y Empresa" (FEDER CGL2015-68963- C2-2-R) and DG \& MG were supported by CYTED program (Red Temática 418RT0555).

Author contributions RDSB, TLM and MG conceived the study. RDSB and DG developed the sampling design, methodology and the analytical framework, and interpreted results. RDSB collected and analyzed the data and wrote the first manuscript. DG revised the first manuscript and all authors revised and improved the final version.

\section{Compliance with ethical standards}

Conflict of interest The authors declare that they have no conflict of interest.

$\begin{array}{lll}\text { Journal : Medium 11258 } & \text { Dispatch : 28-1-2020 } & \text { Pages : 14 } \\ \text { Article No. : } \mathbf{1 0 0 6} & \square \text { LE } & \square \text { TYPESET } \\ \text { MS Code : VEGE-D-19-00353R1 } & \checkmark \text { CP } & \checkmark \text { DISK }\end{array}$




\section{References}

A.S.F.D, (1959) L'Azienda di Stato per le Foreste Demaniali. Edizione A.B.E.T.E, Roma

Abadie J, Dupouey J-L, Avon C, Rochel X, Tatoni T, Bergès L (2018) Forest recovery since 1860 in a Mediterranean region: drivers and implications for land use and land cover spatial distribution. Landsc Ecol 33:289-305

Acácio V, Holmgren M, Jansen PA, Schrotter O (2007) Multiple recruitment limitation causes arrested succession in Mediterranean Cork oak Systems. Ecosystems 10:1220-1230

Adler P, Raff D, Lauenroth W (2001) The effect of grazing on the spatial heterogeneity of vegetation. Oecologia 128:465-479

Alias S, Bianchi L, Calamini G, Gregori E, Sioni S (2010) Shrub facilitation of Quercus ilex and Quercus pubescens regeneration in a wooded pasture in central Sardinia (Italy). iForest 3(1):16-22

Allen CR, Angeler DG, Cumming GS, Folke C, Twidwell D, Uden DR (2016) Quantifying spatial resilience. J Appl Ecol 53:625-635

Alodos CL, Pueyo Y, Barrantes O, Escós J, Giner L, Robles AB (2004) Variations in landscape patterns and vegetation cover between 1957 and 1994 in a semiarid Mediterranean ecosystem. Landsc Ecol 19:543-559

Álvarez-Martínez JM, Suárez-Seoane S, Stoorvogel JJ, de Luis CE, Gilliam F (2014) Influence of land use and climate on recent forest expansion: a case study in the EurosiberianMediterranean limit of north-west Spain. J Ecol 102:905-919

Amici V, Santi E, Filibeck G, Diekmann M, Geri F, Landi S, Scoppola A, Chiarucci A, Vetaas O (2013) Influence of secondary forest succession on plant diversity patterns in a Mediterranean landscape. J Biogeogr 40:2335-2347

Andivia E, Villar-Salvador P, Tovar L, Rabasa S, Rey Benayas JM (2017) Multiscale assessment of woody species recruitment in Mediterranean shrublands: facilitation and beyond. J Veg Sci 28:639-648

Anselin L, Syabri I, Kho Y (2006) GeoDa: an introduction to spatial data analysis. Geogr Anal 38:5-22

Bacaro G, Rocchini D, Bonini I, Marignani M, Maccherini S, Chiarucci A (2008) The role of regional and local scale predictors for plant species richness in Mediterranean forests. Plant Biosyst 142:630-642

Badalamenti E, La Mantia T, La Mantia G, Cairone A, La Mela Veca D (2017) Living and dead aboveground biomass in Mediterranean forests: evidence of old-growth traits in a Quercus pubescens willd. s.l. stand. Forests 8(6): 187

Baeza MJ, Valdecantos A, Alloza JA, Vallejo VR (2007) Human disturbance and environmental factors as drivers of long-term post-fire regeneration patterns in Mediterranean forests. J Veg Sci 18:243-252

Bakker ES, Olff H, Vandenberghe C, De Maeyer K, Smit R, Gleichman JM, Vera FWM (2004) Ecological anachronisms in the recruitment of temperate light-demanding tree species in wooded pastures. J Appl Ecol 41:571-582

Bashan D, Bar-Massada A (2017) Regeneration dynamics of woody vegetation in a Mediterranean landscape under different disturbance-based management treatments. Appl Veg Sci 20:106-114

Berdugo M, Kéfi S, Soliveres S, Maestre FT (2017) Plant spatial patterns identify alternative ecosystem multifunctionality states in global drylands. Nat Ecol Evolut 1(2):0003

Bianchetto E, Buscemi I, Corona P, Giardina G, La Mantia T, Pasta S (2015) Fitting the stocking rate with pastoral resources to manage and preserve Mediterranean forestlands: a case study. Sustainability 7:7232-7244

Bonet A, Pausas JG (2004) Species richness and cover along a 60 -year chronosequence in old-fields of southeastern Spain. Plant Ecol 174:257-270

Bueno RS, Guevara R, Ribeiro MC, Culot L, Bufalo FS, Galetti M (2013) Functional redundancy and complementarities of seed dispersal by the last neotropical Megafrugivores. PLoS ONE 8:e56252

Carmel Y, Flather CH (2004) Comparing landscape scale vegetation dynamics following recent disturbance in climatically similar sites in California and the Mediterranean basin. Landsc Ecol 19:573-590

Carmel Y, Kadmon R (1999) Effects of grazing and topography on long-term vegetation changes in a Mediterranean ecosystem in Israel. Plant Ecol 145:243-254

Carmel Y, Kadmon R, Nirel R (2001) Spatiotemporal predictive models of mediterranean vegetation dynamics. Ecol Appl $11: 268-280$

Chuang WC, Garmestani A, Eason TN, Spanbauer TL, FriedPetersen HB, Roberts CP, Sundstrom SM, Burnett JL, Angeler DG, Chaffin BC, Gunderson L, Twidwell D, Allen CR (2018) Enhancing quantitative approaches for assessing community resilience. J Environ Manage 213:353-362

Debussche M, Escarré J, Lepart J (1982) Ornithochory and plant succession in mediterranean abandoned orchards. Vegetatio 48:255-266

Dormann FC, McPherson MJ, Araújo BM, Bivand R, Bolliger J, Carl G, Davies GR, Hirzel A, Jetz W, Daniel Kissling W, Kühn I, Ohlemüller R, Peres-Neto RP, Reineking B, Schröder B, Schurr MF, Wilson R (2007) Methods to account for spatial autocorrelation in the analysis of species distributional data: a review. Ecography 30(5):609-628

Falcucci A, Maiorano L, Boitani L (2007) Changes in landuse/land-cover patterns in Italy and their implications for biodiversity conservation. Landsc Ecol 22:617-631

Fedriani JM, Wiegand T, Delibes M (2010) Spatial pattern of adult trees and the mammal-generated seed rain in the Iberian pear. Ecography 33(3):545-555

Fotelli MN, Geßler A, Peuke AD, Rennenberg H (2001) Drought affects the competitive interactions between Fagus sylvatica seedlings and an early successional species, Rubus fruticosus: responses of growth, water status and $\delta 13 \mathrm{C}$ composition. New Phytol 151:427-435

Gallego Fernández JB, Mora RG, M., and García Novo F. (2004) Vegetation dynamics of Mediterranean shrublands in former cultural landscape at Grazalema Mountains, South Spain. Plant Ecol 172:83-94

Garcia D, Obeso JR (2003) Facilitation by herbivore-mediated nurse plants in a threatened tree, Taxus baccata: local effects and landscape level consistency. Ecography 26:739-750

\begin{tabular}{|l|lll|}
\hline & Journal : Medium 11258 & Dispatch : 28-1-2020 & Pages : 14 \\
Article No. : $\mathbf{1 0 0 6}$ & $\square$ LE & $\square$ TYPESET \\
MS Code : VEGE-D-19-00353R1 & $V_{\mathrm{CP}}$ & $\checkmark$ DISK \\
\hline
\end{tabular}


Garcia D, Zamora R, Amico GC (2011) The spatial scale of plant-animal interactions: effects of resource availability and habitat structure. Ecol Monogr 81:103-121

García C, Moracho E, Díaz-Delgado R, Jordano P, Matlack G (2014) Long-term expansion of juniper populations in managed landscapes: patterns in space and time. J Ecol 102:1562-1571

Getzin S, Wiegand T, Wiegand K, He F (2008) Heterogeneity influences spatial patterns and demographics in forest stands. J Ecol 96:807-820

Gianguzzi L, La Mantia A (2004) Le serie di vegetazione della riserva Bosco Ficuzza, Rocca Busambra, Bosco del Cappeliere e Gorgo del Drago Provincia di Palermo. Nat Sicil 28(1):265-326

Gómez-Aparicio L (2008) Spatial patterns of recruitment in Mediterranean plant species: linking the fate of seeds, seedlings and saplings in heterogeneous landscapes at different scales. J Ecol 96:1128-1140

González-Varo JP, Carvalho CS, Arroyo JM, Jordano P (2017) Unravelling seed dispersal through fragmented landscapes: Frugivore species operate unevenly as mobile links. Mol Ecol 26:4309-4321

Holl KD, Reid JL, Oviedo-Brenes F, Kulikowski AJ, Zahawi RA (2018) Rules of thumb for predicting tropical forest recovery. Appl Veg Sci 21:669-677

Hu Y-H, Lan G-Y, Sha L-Q, Cao M, Tang Y, Li Y-D, Xu D-P (2012) Strong neutral spatial effects shape tree species distributions across life stages at multiple scales. PLoS ONE 7:e38247

Jordano P (2017) What is long-distance dispersal? And a taxonomy of dispersal events. J Ecol 105:75-84

Keitt TH (2003) Spatial autocorrelation, dispersal and the maintenance of source-sink populations. In: Bradshaw GA, Marquet PA (eds) How landscapes change: human disturbance and ecosystem fragmentation in the Americas. Springer, Berlin Heidelberg, Berlin, Heidelberg, pp 225-238

Keitt TH, Bjørnstad ON, Dixon PM, Citron-Pousty S (2002) Accounting for spatial pattern when modeling organismenvironment interactions. Ecography 25:616-625

Kissling WD, Carl G (2008) Spatial autocorrelation and the selection of simultaneous autoregressive models. Glob Ecol Biogeogr 17(1):59-71

La Mantia T, Bueno RS (2016) Colonization of eurasian jay Garrulus glandarius and holm oaks Quercus ilex: the establishment of ecological interactions in urban areas. Avocetta 40:85-87

La Mantia T, Rühl J, Pasta S, Campisi DG, Terrazzino G (2008) Structural analysis of woody species in Mediterranean old fields. Plant Biosyst 142:462-471

La Mantia T, Gristina L, Rivaldo E, Pasta S, Novara A, Rühl J (2013) The effects of post-pasture woody plant colonization on soil and aboveground litter carbon and nitrogen along a bioclimatic transect. iForest 6(5):238-246

La Mantia T, Rühl J, Massa B, Pipitone S, Lo Verde G, Bueno RS (2019) Vertebrate-mediated seed rain and artificial perches contribute to overcome seed dispersal limitation in a Mediterranean old field. Restor Ecol 27(6):1393-1400

Laskurain NA, Aldezabal A, Olano JM, Loidi J, Escudero A (2013) Intensification of domestic ungulate grazing delays secondary forest succession: evidence from exclosure plots. J Veg Sci 24:320-331

Lasky JR, Keitt TH (2012) The effect of spatial structure of pasture tree cover on Avian frugivores in eastern Amazonia. Biotropica 44:489-497

Martínez D, García D (2015) Changes in the fruiting landscape relax restrictions on endozoochorous tree dispersal into deforested lands. Appl Veg Sci 18:197-208

Martínez-Duro E, Ferrandis P, Escudero A, Luzuriaga AL, Herranz JM (2010) Secondary old-field succession in an ecosystem with restrictive soils: does time from abandonment matter? Appl Veg Sci 13:234-248

Massa B, La Mantia T (2007) Forestry, pasture, agriculture and fauna correlated to recent changes in Sicily. Forest 4(4):418-438

Méndez M, García D, Maestre FT, Escudero A (2008) More ecology is needed to restore Mediterranean ecosystems: a reply to valladares and gianoli. Restor Ecol 16:210-216

Navarro-González I, Pérez-Luque AJ, Bonet FJ, Zamora R (2013) The weight of the past: land-use legacies and recolonization of pine plantations by oak trees. Ecol Appl 23:1267-1276

Ne'eman G, Izhaki I (1996) Colonization in an abandoned EastMediterranean vineyard. J Veg Sci 7:465-472

Novara A, Gristina L, Sala G, Galati A, Crescimanno M, Cerdà A, Badalamenti E, La Mantia T (2017) Agricultural land abandonment in Mediterranean environment provides ecosystem services via soil carbon sequestration. Sci Total Environ 576:420-429

Olff H, Vera FWM, Bokdam J, Bakker ES, Gleichman JM, de Maeyer K, Smit R (1999) Shifting mosaics in grazed woodlands driven by the alternation of plant facilitation and competition. Plant Biol 1:127-137

Pausas JG, Millán MM (2019) Greening and browning in a climate change hotspot: the Mediterranean basin. Bioscience 69(2):143-151

Pausas JG, Bonet A, Maestre FT, Climent A (2006) The role of the perch effect on the nucleation process in Mediterranean semi-arid oldfields. Acta Oecol 29:346-352

Perry JN, Dixon PM (2002) A new method to measure spatial association for ecological count data. EcoScience 9:133-141

Perry JN, Winder L, Holland JM, Alston RD (1999) Red-blue plots for detecting clusters in count data. Ecol Lett 2:106-113

Plieninger T, Hui C, Gaertner M, Huntsinger L (2014) The impact of land abandonment on species richness and abundance in the Mediterranean basin: a meta-analysis. PLoS ONE 9:e98355

Pueyo Y, Begueria S (2007) Modelling the rate of secondary succession after farmland abandonment in a Mediterranean mountain area. Landsc Urban Plan 83:245-254

QGIS Development Team (2016) QGIS geographic information system. Open Source Geospatial Foundation Project. https://qgis.osgeo.org

Quero JL, Herrero A, Zamora R (2011) Linking stochasticity to determinism of woody plant recruitment in a mosaic landscape: a spatially explicit approach. Basic Appl Ecol 12:161-171

\begin{tabular}{|l|lll|}
\hline & Journal : Medium 11258 & Dispatch : 28-1-2020 & Pages : 14 \\
Article No. : 1006 & $\square$ LE & $\square$ TYPESET \\
MS Code : VEGE-D-19-00353R1 & $\checkmark \mathrm{CP}$ & $\checkmark$ DISK \\
\hline
\end{tabular}


Raimondi S, Dazzi C, Cirrito V (1983) Modello di studio integrato del territorio (Ficuzza-Palermo), nota n.5. I suoli. Quaderni di Agronomia 10:89-131

Rivas-Martínez S (2008) Global bioclimatics (Clasificación biclimática de la Tierra) (versión 01-12-2008). www. globalbioclimatics.org., www.globalbioclimatics.org.

Seifan M, Kadmon R (2006) Indirect effects of cattle grazing on shrub spatial pattern in a mediterranean scrub community. Basic Appl Ecol 7:496-506
Sluiter R, de Jong SM (2007) Spatial patterns of Mediterranean land abandonment and related land cover transitions. Landsc Ecol 22:559-576

Ver Hoef JM, Peterson EE, Hooten MB, Hanks EM, Fortin M-J (2018) Spatial autoregressive models for statistical inference from ecological data. Ecol Monogr 88:36-59

Publisher's Note Springer Nature remains neutral with regard to jurisdictional claims in published maps and institutional affiliations.

\begin{tabular}{|l|lll|}
\hline Journal : Medium 11258 & Dispatch : 28-1-2020 & Pages : 14 \\
Article No. : 1006 & $\square$ LE & $\square$ TYPESET \\
MS Code : VEGE-D-19-00353R1 & $\checkmark \mathrm{CP}$ & $\checkmark$ DISK \\
\hline
\end{tabular}

